\title{
1 Sex-biased parasitism and expression of a sexual signal
}

3 Adam A. Rosso ${ }^{1 \dagger}$, Daniel J. Nicholson ${ }^{2 \dagger}$, Michael L. Logan ${ }^{3,4}$, Albert K. Chung ${ }^{1,5}$, John David

4 Curlis $^{1,6}$, Zachariah M. Degon ${ }^{1}$, Robert J. Knell ${ }^{2}$, Trenton W. J. Garner ${ }^{7}$, W. Owen McMillan ${ }^{3}$, 5 and Christian $\mathrm{L} \mathrm{Cox}^{1,8 * \dagger}$

6

$7 \quad$ 'Both authors contributed equally to this work

8

$9 \quad{ }^{1}$ Department of Biology, Georgia Southern University, Statesboro, GA, USA

$10 \quad{ }^{2}$ School of Biological and Chemical Sciences, Queen Mary University of London, London, UK

$11{ }^{3}$ University of Nevada-Reno, Reno, Nevada, USA

$12 \quad{ }^{4}$ Smithsonian Tropical Research Institute, Panama City, Panama

$13{ }^{5}$ University of California Los Angeles, Los Angeles, California, USA

$14{ }^{6}$ University of Michigan, Ann Arbor, Michigan, USA

$15 \quad{ }^{7}$ Institute of Zoology, Zoological Society of London, London, UK

$16{ }^{8}$ Institute of Environment and Department of Biological Sciences, Florida International

17 University, Miami, Florida, USA

18

$19 *$ Corresponding author: Christian L. Cox, Department of Biological Sciences, Florida

20 International University, Miami, FL, USA, 33199 (ccox@ fiu.edu)

21

22 Running title: Parasitism and sexual signals

23 
24 Because sexual signals are often expressed more highly in one sex than the other, they can

25 impose a sex-specific cost of reproduction through parasitism. While the two primary paradigms

26 regarding the relationship of parasites to sexual signals are the good-genes hypothesis and the

27 immunocompetence handicap hypothesis, there are other ecological, morphological, and

28 energetic factors that may influence parasite infections in a sex-specific fashion. We tested the

29 relationship between expression of a sexual signal (the dewlap) and ecological, morphological,

30 and energetic factors mediating ectoparasite (mite) load between male and female Panamanian

31 slender anoles (Anolis apletophallus). We found that males were more highly parasitized than

32 females because of the preponderance of ectoparasites on the larger dewlap of males. Indeed,

33 ectoparasite infection increased with both body size and dewlap size in males but not females,

34 and parasite infection was related to energy storage in a sex-specific fashion for the fat bodies,

35 liver, and gonads. Our work and previous work on testosterone in anoles suggest that this pattern

36 did not arise solely from immunosuppression by testosterone, but that mites prefer the dewlap as

37 an attachment site. Thus, the expression of this sexual signal could incur a fitness cost that may

38 structure life-history tradeoffs.

40 Keywords: Immunocompetence handicap hypothesis, good-genes hypothesis, ectoparasite, mite, 41 anole, Anolis 


\section{INTRODUCTION}

Sexual signals, which are any trait that attracts mates and increases fitness through reproduction, are a ubiquitous form of phenotypic diversity in nature (Symonds \& Elgar, 2007;

47 Seddon et al., 2013; Schaefer \& Ruxton, 2015). Because they are linked strongly to reproduction and thus fitness, many organisms invest heavily in sexual signals, even to the extent of incurring

49 survivorship costs (Fisher, 1930; Ryan et al., 1982; Hoefler et al., 2007). Sexual signals are often 50 (but not always) present or highly expressed in only one of the sexes (e.g., breeding turbercles in 51 fish; Taskinen \& Kortet, 2002; dewlaps of anoles, Harrison \& Poe, 2012; bird coloration, Dale et 52 al., 2015), highlighting the potential of sexual signals to impose sex-specific fitness costs. One mechanism whereby sexual signal expression can modulate fitness is through their relationship 54 to parasitism. Parasites can be a powerful selective force that can reduce performance, survival, 55 and reproduction (Schall, 1983; Richner et al., 1993; Brown et al., 1995; Lamarre et al., 2018; 56 Edworthy et al., 2019; Jones et al., 2019) in a sex-specific fashion (Smith, 1996; Perez-Orella \& 57 Schulte-Hostedde, 2005; Reedy et al., 2016).

There are many paradigms that have been used to understand the relationship between 59 parasites and sexual signals. First, Hamilton and Zuk (1982) proposed that sexual ornamentation 60 can be used as an honest signal of the ability of an individual to resist parasitic infection. This so-

61 called "good genes" hypothesis generally predicts that as the quality of the sexual signal 62 increases, parasite load should decrease (Hamilton \& Zuk, 1982), assuming that good genes are 63 associated with parasite resistance and not merely increased tolerance. This hypothesis has been 64 tested widely and has found support among diverse taxa (e.g., turkeys, Buchholz, 1995; roach 65 fishes, Taskinen \& Kortet, 2002; bowerbirds, Doucet \& Montgomerie, 2003; anole lizards, Cook 66 et al., 2013b). The second paradigm is the immunocompetence handicap hypothesis, which 
67 proposes that pleiotropic hormones, such as testosterone in vertebrates, mediate a tradeoff

68 between immunocompetence and quality of a sexual signal (Folstad \& Karter, 1992).

69 Mechanistically, this is because testosterone can stimulate expression of sexual signals (Fernald,

70 1976; Cox et al., 2005; Lindsay et al., 2011; Cox et al., 2015a), but is also immunosuppressive

71 (Folstad \& Karter, 1992; Muehlenbein \& Bribiescas, 2005). The immunocompetence handicap

72 hypothesis generally predicts that parasite load should increase with the quality or size of a

73 sexual signal (Folstad \& Karter, 1992) as hormones such as testosterone can mediate a shift in

74 energetics from investment in the immune system to reproduction (Boughton et al., 2007; Cox et

75 al., 2015a; Cox et al., 2015b; Reedy et al., 2016). Like the good genes hypothesis, there is also

76 broad support for this hypothesis among diverse taxa (e.g., Psammodromus lizards, Salvador et

77 al., 1996; house sparrows, Poiani et al., 2000; damselflies, Siva-Jothy, 2000; humans, Rantala et

78 al., 2012). Rather than representing strict alternatives, the good genes hypothesis and

79 immunocompetence handicap hypothesis represent ends of a continuum between honest

80 signaling of mate quality (good-genes hypothesis) and tradeoffs regulating expression of sexual

81 signals (immunocompetence handicap hypothesis). However, other ecological and

82 morphological factors can impose a sex-specific ectoparasite cost of reproduction that are not

83 directly linked to immunosuppression by testosterone.

84 Parasite infection can also be modulated by ecological and morphological factors that

85 alter the susceptibility of hosts or encounter rate between hosts and parasites in a sex-specific

86 fashion. Microhabitat or dietary differences between the sexes can alter the likelihood of

87 infection if certain microhabitats contain more parasites or allow more efficient infection of hosts

88 (Wiles et al., 2000; Durden et al., 2004; Biaggini et al., 2009; Leung \& Koprivnikar, 2016; Jones

89 et al., 2019). Morphological differences between host sexes can also impact parasite infection 
through differences in attachment sites available to ectoparasites (e.g., body size, organ size, or

91

92 ideal attachment sites for ectoparasites). For example, ectoparasites such as mites and ticks are often more abundant on larger individuals (Bauwens et al., 1983; Rocha et al., 2008), which has clear ramifications for sex-specific parasitism in species where the sexes differ in body size (Dudek et al., 2016). Alternatively, parasites can cluster in preferred locations for feeding and defense (Spears et al., 1999; Wiles et al., 2000; Jovani et al., 2006; Dudek et al., 2016), and some morphological features can concentrate mite infections on certain locations on the body such as "mite pockets" (Jovani \& Serrano, 2001; Jovani \& Serrano, 2004; Jovani et al., 2006; Rocha et al., 2008). Therefore, morphological features such as sexual signals that are dimorphic in expression could increase sex-biased infection by parasites. Finally, parasite infection can be influenced by the energetic state of the host, which in turn is influenced by ecological (e.g., differences in food availability between sex-specific habitats) and morphological factors (i.e., size of fat storage organs) that can differ between the sexes (Gross \& Fritz, 1982; Sikkel et al., 2000; Lajeunesse et al., 2004; Reedy et al., 2016) and can explain sex-differences in parasitism in some species (Reedy et al., 2016).

We sought to understand how ecology, morphology, and energetics can impact ectoparasitic infection in a sex-specific fashion in the Panamanian slender anole (Anolis apletophallus; hereafter, slender anole). The slender anole possesses a dramatic sexual signal (the dewlap), can be heavily parasitized by trombiculid mites (Cox et al., 2020), and is sexually monomorphic in body size (Andrews \& Stamps, 1994). In other anole species with male-biased sexual size dimorphism, testosterone circulates at higher levels in males (Lovern et al., 2001; Cox et al., 2009a; Cox et al., 2017), expression of the dewlap can be condition-dependent and is regulated by testosterone (Lovern et al., 2004; Cox et al., 2009b; Cox et al., 2015a; Curlis et al., 
113 2017), and males suffer from increased ectoparasitism (Zippel et al., 1996; Reedy et al., 2016).

114 However, whether increased ectoparasites is due to immunosuppression or simply an increase in

115 surface area and body mass in males is difficult to disentangle in species with sexual size

116 dimorphism. Hence, the highly sexually dimorphic expression of the dewlap in a generally

117 sexually monomorphic lizard renders this species an ideal system for studying the relationship

118 between ectoparasitism and sexual signals. We combined field surveys and laboratory

119 dissections to address the following questions: 1) Is the relationship between sexual signals and

120 ectoparasites consistent with honest signaling or fitness tradeoffs between signal expression and

121 ectoparasite infection? 2) Do male and female slender anoles differ in ectoparasite load and are

122 ectoparasites distributed differently on their bodies? 3) Is variation in habitat use, field-active

123 body temperature, and energetics among individuals correlated with ectoparasite infection? We

124 found evidence of sex-biased parasitism that was driven by the larger dewlap of male slender

125 anoles compared to females, and ectoparasitic infections were further modulated by both

126 morphology and energetics in a sex-specific fashion.

127

\section{MATERIALS AND METHODS}

\section{STUDY SYSTEM}

The slender anole is a small $(\sim 1.5 \mathrm{~g})$, insectivorous lizard that is found in lowland,

131 closed-canopy forests in eastern and central Panama (Kohler \& Sunyer, 2008). Slender anoles

132 are short-lived ( 10 month generation time) and are extremely abundant (the most abundant

133 vertebrate; Rand \& Myers, 1990) in their forested habitat (Andrews \& Nichols, 1990; Andrews,

134 1991). While this species is sexually monomorphic in most traits, including body size and

135 coloration (Andrews \& Stamps, 1994), males have a large dewlap (Fig. 1; Stapley et al., 2011), 
which is a colorful and extendable flap of skin in the gular region that functions as a social and sexual signal (Kohler \& Sunyer, 2008; Stapley et al., 2011). In contrast, female slender anoles have either a very small dewlap (Figure 1) or none at all (Kohler \& Sunyer, 2008). Males also have larger home ranges, disperse farther, and tend to perch higher in the vegetation than females (Talbot, 1979; Andrews \& Rand, 1983), which could alter their risk of parasite infections. Both sexes can be heavily parasitized (Fig. 1) by both endo- and ectoparasites (Telford, 1974; Cox et al., 2020), including the trombiculid mite (Eutrombiculus c.f. alfreddugesi., Lance Durden pers. comm). Anoles do not have mite pockets (areas of scale-less skin that tend to concentrate ectoparasite infections), unlike many other lizard genera (Arnold, 1986). Mite infestations vary seasonally in some temperate species of lizards (Werman, 1983; Klukowski, 2004; Huyghe et al., 2010; Lumbad et al., 2011). However it is unknown whether mite infestations vary between wet and dry seasons for the tropical slender anole, although they do not vary seasonally for a different species of tropical lizard (Heredia et al., 2014). Trombiculid mites pierce the integument of the lizard with at tube called a stylostome to inject saliva and digestive enzymes (Arnold, 1986) and consume the resulting mixture of blood, lymph, and dissolved cells (Arnold, 1986). These ectoparasite infections in lizards cause integumental lesions (Goldberg \& Bursey, 1991; Goldberg \& Holshuh, 1992), alter social and thermoregulatory behavior (Cook et al., 2013b; Johnson et al., 2019), can decrease growth and body condition (Curtis \& Baird, 2008; Cook et al., 2013a), and act as vectors for diseases (Arnold, 1986). Trombiculid mite infections can also instigate an immune response in vertebrates (Wright et al., 1988), and induce lesions in lizards that are likely a reaction of the immune system (Arnold, 1986; Goldberg \& Bursey, 1991; Goldberg \& Holshuh, 1992).

FieLd COLLECTION 
We collected most slender anoles during surveys in Soberanía National Park, Panama,

160

161

162

163

164

165

166

167

168

169

170

171

172

173

174

175

176

177

178

179

180 during the wet season in July 2017, with an additional collection period in July 2018. This period

of time is during the primary reproductive period in slender anoles (Andrews \& Rand, 1974;

Andrews, 1979). Adult lizards were captured either by hand (Moseley et al., 2015) or by a lizard

catch-pole, which is comprised of the top section of two-piece fishing rod and a braided fishing

line with a loop created by a slipknot. Upon capture, we determined sex and measured body

temperature, perch height, and perch diameter. We determined sex by the presence of a large

dewlap, which is only present in males. We measured body temperature by inserting a type-K

thermocouple (Omega, Stamford, CT, USA) into the cloaca. We only included body

temperatures in subsequent analyses if we were able to record them within $30 \mathrm{~s}$ (Dzialowski, 2005 ) of capture (98.2\% of lizards). We measured perch height as the distance above the ground where the lizard was initially located to the nearest $\mathrm{cm}$ using an extendable tape measure. Perch diameter was recorded at the location where the lizard was initially detected using digital calipers (Neiko Tools, China) to the nearest mm.

QUANTIFYING ECTOPARASITES, DEWLAPS, AND ENERGY STORAGE

We quantified ectoparasite loads by visually inspecting lizards for the presence of trombiculid mites (Cox et al., 2020). In slender anoles, these small mites are visible to the naked eye and are located on the dewlap, the axillary region, or the inguinal region (Fig. 1). Because anoles have very small scales with minimal overlap, even smaller mites are unlikely to be able to conceal themselves under scales, although it is possible that we did not detect very small larvae.

For each individual lizard, we recorded the total number of mites on each of the three regions by visual inspection (Table S1). 
We measured the size of the dewlap of both males and females. We used forceps to

182

extend the dewlap of each animal over graph paper with a scale and photographed the dewlap.

The dewlap was then digitally traced to the base of the throat using the freehand line tool in the program ImageJ (Schneider et al., 2012) to measure area in $\mathrm{cm}^{2}$. Finally, we measured snoutvent length (Watson et al., 2019) using digital calipers (Neiko Tools, China) and the body mass of each individual to the nearest $0.01 \mathrm{~g}$ using a digital balance (ScoutPro, Ohaus Corporation, Parsippany, New Jersey, USA).

In both 2017 and 2018, we dissected a subset of lizards in our study ( $n=107)$ and quantified the size of several internal organs that are related to energetics and metabolism (Table S2). Specifically, we measured the mass of the discrete visceral fat bodies, liver, and gonads. In squamate reptiles, fat bodies and the liver are both associated with energy storage (Derickson, 1976; Cox et al., 2015a). In males, testis mass represents investment in post-copulatory fitness (Todd, 2008; Kahrl et al., 2016), whereas in females ovary mass represents energetic investment into offspring (Andrews \& Rand, 1974; Cox et al., 2010). Each organ was dissected, lightly blotted once on laboratory tissue (Kimwipe ${ }^{\mathrm{TM}}$, Kimberly-Clark, Irving, TX, USA), and weighed to the nearest gram on tared weighing paper using an analytical balance (Sartorius Handy Analytical Balance, Sartorius AG, Grottingen, Germany).

\section{STATISTICAL METHODS}

We conducted analyses on mite abundance, mite prevalence, and mite intensity. Mite abundance is the total number of mites on each lizard (Klukowski, 2004). Mite intensity is the number of mites on lizards that have mites, excluding animals with zero mites (Diaz-Real et al., 2014; Reedy et al., 2016; Cox et al., 2020). Mite prevalence is the proportion of lizards that have mites at a population level, which is analyzed at an individual level as a binary variable that 
204 represents presence or absence of mites on an individual (Diaz-Real et al., 2014; Reedy et al., 205 2016; Cox et al., 2020). These three measures of mite infection are useful for characterizing 206 overall mite load (mite abundance), the relative severity of mite infections on infected lizards 207 (mite intensity), and rate of mite infection (mite prevalence). We analyzed mite abundance, 208 intensity and prevalence for the entire lizard as well as separated by body region (dewlap, 209 axillary, and inguinal regions). We used linear regression models (ANOVA or regression) on 210 response variables that were normally or log-normally distributed, such as body size, perch

211 height and width, and body temperature. Because of the high frequency of lizards without mites, 212 continuous ectoparasite data were not normally distributed and possessed a strong right skew.

213 Therefore, we conducted generalized linear model analyses when the response variable was mite 214 abundance or intensity, which allowed the specification of the Poisson distribution through a log-

215 link function. Because presence/absence (i.e. prevalence) of mites is a binary variable, we used 216 either nominal logistic regression or contingency analyses when mite presence/absence was a 217 response variable. Independent variables included sex, ecology, morphology, and organ mass 218 data, with body size and other covariates as appropriate. Details of statistical models are in 219 Tables 1-4. Finally, we confirmed the major results of our analyses using bivariate non220 parametric analyses (e.g. Kruskal Wallis, Spearman's Rank Correlation). Variables were log221 transformed as necessary prior to analysis to meet the assumptions of statistical models. All 222 analyses were completed in JMP v13.0 (SAS Institute, Cary, North Carolina, USA). 
We found that males were more heavily parasitized than females, which was driven by

227 heavy ectoparasite load on male dewlaps. We captured 515 Panamanian slender anoles (232

228 females, 279 males) of which $366(71 \%)$ were infected with ectoparasitic trombiculid mites.

229 Males were significantly (contingency analysis of mite prevalence; $\chi^{2}=12.335, P=0.0004$ ) more

230 likely (prevalence of $77.5 \%$ ) to be infected than females (prevalence of 63.4\%, Fig. 2), and males

231 had significantly (generalized linear model of mite abundance; $\chi^{2}=486.7, P<0.0001$, Wilcoxon

232 test; $\mathrm{Z}=-6.04, P<0.0001)$ more mites than females (Fig. 2). Infected males (range of 1-54 mites,

233 median of 9 mites) also had significantly more mites than females (range of 1-24 mites, median

234 of 5 mites) that were infected (generalized linear model with mite intensity; $\chi^{2}=262.6, P<0.0001$,

235 Wilcoxon test; $\mathrm{Z}=-5.44, P<0.0001)$. This pattern was driven by the fact that dewlaps of males

236 were significantly more likely to have mites than those of females (contingency analysis of mite

237 prevalence; $\left.\chi^{2}=12.335, P=0.0004\right)$, and male dewlaps were significantly more parasitized than

238 female dewlaps (generalized linear model of mite abundance; $\chi^{2}=385.2, P<0.0001$, Wilcoxon

239 test; $\mathrm{Z}=-8.37, P<0.0001)$. Considering only dewlaps with mite infestations, dewlaps of males

240 also had significantly more mites than the infected dewlaps of females (generalized linear model

241 of mite intensity; $\chi^{2}=92.7, P<0.0001$, Wilcoxon test; $\left.Z=-4.35, P<0.0001\right)$. Interestingly, females

242 were significantly more likely to be parasitized in the axillary (contingency analysis of mite

243 prevalence; $\chi^{2}=28.2, P<0.0001$ ) and inguinal regions than males (contingency analysis of mite

244 prevalence; $\chi^{2}=20.2, P<0.0001$ ) and had significantly more mites in the axillary (generalized

245 linear model of mite abundance; $\chi^{2}=63.1, P<0.0001$, Wilcoxon test; $\left.\mathrm{Z}=5.44, P<0.0001\right)$ and

246 inguinal regions (generalized linear model of mite abundance; $\chi^{2}=56.3, P<0.0001$, Wilcoxon test;

$247 \mathrm{Z}=4.7, P<0.0001)$. For animals with mites in the axillary region, the intensity of infection in the

248 axillary region did not differ between the sexes (generalized linear model of mite intensity; 
$249 \chi^{2}=1.7, P=0.1898$, Wilcoxon test; $\left.\mathrm{Z}=-1.75, P=0.0804\right)$, although females had slightly greater

250 intensity than males (Fig. 2). However, females had greater intensity of infection in the inguinal

251 region than males (generalized linear model of mite intensity; $\chi^{2}=4.3, P=0.0382$, Wilcoxon test;

$252 \mathrm{Z}=-2.12, P=0.0343)$.

253

ECOLOGICAL CORRELATES OF ECTOPARASITE INFECTION

255

We found that ecological factors did not impact mite abundance, mite prevalence, or mite

256 intensity. Males were found on significantly higher perches (linear regression model;

$257 \quad F_{1,486}=54.24, P<0.0001$, Wilcoxon test; $\left.\mathrm{Z}=--7.10, P<0.0001\right)$ and had marginally warmer body

258 temperatures (linear regression model; $F_{1,504}=4.16, P=0.0478$, Wilcoxon test; $\mathrm{Z}=-1.61$,

$259 P=0.1069)$ than females, but perch diameter did not differ between the sexes (linear regression

260 model; $F_{1,466}=0.644, P=0.4225$, Wilcoxon test; $\left.\mathrm{Z}=-0.23, P=0.8150\right)$. We found that there was no

261 main effect of body temperature, perch height, or perch diameter on the mite prevalence,

262 abundance, or intensity, although the sexes still differed in mite prevalence, abundance and

263 intensity when controlling for habitat by including perch diameter in the statistical models (Table

264 1). We did detect an interaction between sex and body temperature on mite abundance, and

265 between sex and both perch diameter and body temperature on mite intensity (Table 1),

266 suggesting that habitat and thermal physiology could have a minor role in mite infections.

267

MORPHOLOGICAL CORRELATES OF ECTOPARASITES

We found that mite infection increased with size and that the relationship between size

270 and mite infection differed between the sexes (Fig. 3). Females (1.55 $\pm 0.02 \mathrm{~g}$ ) were slightly

271 heavier than males $\left(1.48 \pm 0.02 \mathrm{~g}, F_{1,513}=6.03, P=0.0144\right)$, but sexes did not differ in snout-vent 
272 length (log-transformed SVL; $\left.F_{1,513}=3.43, P=0.0647\right)$. However, mite prevalence increased

273 significantly with body size in both sexes (Fig. 3, Table 2). Mite abundance increased with SVL

274 and body mass (Fig. 3, Table 2), but the strength of this relationship differed between males and

275 females (Fig. 3, Table 2, significant sex by size interaction). Similarly, the number of mites on

276 infected lizards also increased with SVL and body mass (mite intensity, Table 2) for males but

277 not for females (Fig. 3, Table 2, significant sex by size interactions, confirmed with separate

278 analyses for the sexes). When mite infections on body regions were analyzed separately, mite

279 infection increased with body size for the dewlap (mite abundance, intensity, and prevalence)

280 and axillary regions (abundance and intensity), but not the inguinal region (Table 2).

281 Interestingly, we found a sex-specific relationship between body size and mite infection

282 (abundance, intensity, and prevalence) for the dewlap (significant sex by body size interaction,

283 Table 2), but not other body regions.

284 We found that the mite abundance and intensity of mite infection increased with the size

285 of the dewlap for males but not for females (significant main effect of dewlap area, Fig. 4, Table

286 3). The size of the dewlap was not related to the prevalence of mite infection in males or females

287 (Table 3). Because the relationship between dewlap size and mite infection appeared to be non-

288 linear (Fig. 4), we constructed a statistical model a posteriori that included a quadratic dewlap

289 term. This analysis indicated that males with the largest dewlaps tended to have decreasing

290 numbers of mites (generalized linear model of mite abundance; dewlap area, $\chi^{2}=7.77, P=0.0053$;

291 SVL, $\chi^{2}=63.10, P<0.0001$; dewlap area by SVL, $\chi^{2}=7.95, P=0.0048$; dewlap area by dewlap

292 area, $\chi^{2}=27.21, P<0.0001$ ), but not females (generalized linear model of mite abundance; dewlap

293 area, $\chi^{2}=0.02, P=0.8961 ; \mathrm{SVL}, \chi^{2}=14.64, P=0.0001$; dewlap area by $\mathrm{SVL}, \chi^{2}=0.02, P=0.8948$;

294 dewlap area by dewlap area, $\chi^{2}=2.25, P=0.1337$ ). Use of LOWESS (locally weighted scatterplot 
smoothing) curves confirmed the linear and nonlinear components to the relationship between mite abundance and dewlap size for males, but not females (Fig. 4). Most of the effect of dewlap area on mite abundance seems to be driven by the fact that larger dewlaps have greater mite abundance in males but not females (significant main effect of dewlap area, Table 3), but infected lizards do not experience increased dewlap mite number with larger dewlaps (dewlap mite intensity, Table 3). Interestingly, we also found that the size of the dewlaps was positively associated with mite prevalence in the axillary region (significant main effect of dewlap area, Table 3), perhaps because of the physical proximity of the axillary region to the dewlap. Besides axillary mite prevalence, dewlap area was not associated with mite abundance, intensity, or prevalence in the axillary or inguinal regions (Table 3 ).

\section{ENERGY STORAGE, REPRODUCTIVE INVESTMENT, AND ECTOPARASITES}

We found evidence that ectoparasite infection was associated with the mass of organs of energy storage. We found that male anole lizards with larger fat bodies tended to have lower mite abundance and intensity than those with small fat bodies, while fat body mass was not associated with mite abundance or intensity in females (Fig. 5, Table 4). There was no relationship between mite abundance and liver mass for males or females (Table 4). However, liver mass was positively associated with mite intensity for both males and females. While mite abundance and intensity increased with the size of the ovaries in females, testis size was negatively correlated with mite intensity (but not abundance) in males (Fig. 5, Table 4). There was no relationship between mite prevalence and mass of fat bodies, liver, or gonads in either sex (Table 4). 
We found evidence of a sex-specific relationship between parasitism and a sexual signal

319 in a species that is sexually monomorphic in most traits. Importantly, we found that larger sexual

320 signals increased ectoparasite infection in males, but not females. Mite infection was modulated

321 by energetics in a sex-specific fashion on slender anoles, but we found little evidence that

322 ecological differences between the sexes impacted ectoparasitism. Broadly, our results are

323 consistent with the notion that male anoles could pay an ectoparasite-driven fitness cost for large

324 sexual display organs.

325 Because we found that the presence and expression of a sexual signal was associated with

326 increased rather than decreased parasitism, our results are generally congruent with the

327 immunocompetence handicap hypothesis (Folstad \& Karter, 1992) rather than the good genes

328 hypothesis (Hamilton \& Zuk, 1982). However, we did find that the largest dewlaps were

329 associated with a diminished parasite load, which could be consistent with good-genes

330 hypothesis in males with maximal expression of the dewlap. Regardless, while the

331 immunocompetence handicap hypothesis suggests that immunosuppression by testosterone is

332 responsible for the higher mite load in males (Folstad \& Karter, 1992), our results might suggest

333 an indirect mechanism whereby testosterone can increase risk of parasitism. Note that we did not

334 directly measure circulating testosterone levels in slender anoles, and therefore our conclusions

335 with respect to the relationship between ectoparasitism and testosterone-based

336 immunosuppression must be considered preliminary. Nevertheless, there is a strong positive

337 correlation between sexual signal size and circulating testosterone species in many lizard species

338 including anoles (Psammodromus algirus, Salvador et al., 1996; Sceloporus undulatus, Cox et

339 al., 2005; Sceloporus jarrovii, Cox et al., 2008), and hormone implant studies have revealed that

340 both dewlap size and male-typical color is stimulated in many of the Anolis congeners of the 
341 Panamanian slender anole (Anolis carolinensis, Lovern et al., 2004; Anolis sagrei, Cox et al.,

342 2015a). In addition, females of many lizard species (including anoles) have lower circulating

343 testosterone than males (Cox \& John-Alder, 2005; Cox et al., 2009b; Cox et al., 2015a). While

344 female slender anoles are similar in body size to males, they have more mites than males on all

345 body regions (axillary and inguinal) except for the dewlap (Fig. 1). If larger dewlaps of male

346 slender anoles are regulated by testosterone and females have lower circulating testosterone than

347 males (as is the case in other anole species), our work suggests that the increased levels of

348 parasitism experienced by the sex with the larger dewlaps is unlikely to be due solely to

349 immunosuppression.

In the absence of apparent immunosuppression, the increased parasitism of the dewlap in

351 male slender anoles could be caused by the physical characteristics of the dewlap itself.

352 Although the dewlap remains unobtrusively folded most of the time, there is wide spacing of

353 dewlap scales (gorgetal scales) to facilitate dewlap extension, and this spacing would be more

354 pronounced in the larger dewlap of males compared to females. Spacing between the gorgetal

355 scales may allow mites a more propitious attachment location, analogous to how mites cluster in

356 scale-less anatomical regions such as "mite pockets" of other lizard species (Rocha et al., 2008;

357 Dudek et al., 2016), which are hypothesized to concentrate mites and limit damage to the lizard

358 integument (Arnold, 1986; Rocha et al., 2008). Additionally, the folded dewlap might provide

359 additional surface area as well as an ideal microclimatic environment for mites to limit water

360 loss. If mites prefer dewlaps for structural reasons, this provides a novel mechanism inducing

361 sex-specific costs of reproduction.

Our work also documents a sex-specific cost of a sexual signal in a species that is

363 sexually monomorphic for many traits, including body size. Males with larger dewlaps suffered 
364 from increased parasitism (while including a covariate for body size), while dewlap size was not

365 related to parasitism in females. The lack of a relationship between dewlap size and infections in

366 females could be explained by the small size of the dewlap in females, with limited scope for

367 attachment sites for mites. Similarly, we found that mite parasitism increased with body size in

368 males, but not females, even while controlling for dewlap size. Together, this suggests that the

369 cost of parasitism increases with both body size and the size of a sexual signal. Previous research

370 in other lizard species has found that larger body size in males can be associated with increased

371 parasitism (Bauwens et al., 1983; Rocha et al., 2008), but this has primarily been investigated in

372 species that are sexually dimorphic in body size and other traits (Cox \& John-Alder, 2007;

373 Dudek et al., 2016). A positive correlation between parasitism and body size could be caused by

374 parasite accumulation during development and age-specific immune responses (Fichet-Calvet et

375 al., 2003; Hawlena et al., 2006), but the rapid growth and short lifespan of slender anoles limits

376 this possibility. Similarly, other research has found that the size of a sexual signal increases

377 parasitism risk, but this has been associated with underlying correlations between testosterone,

378 expression of a sexual signal and immunosuppression (e.g., Psammodromus lizards, Salvador et

379 al., 1996; Olsson et al., 2000; house sparrows, Poiani et al., 2000; damselflies, Siva-Jothy, 2000;

380 humans, Rantala et al., 2012). Our work highlights how the single dimorphic trait of dewlap size

381 can enhance parasitism risk in a sex-specific fashion for a species where the sexes are otherwise

382 (e.g., length, mass) very similar.

383 We did not find that parasite load was linked to the three habitat variables in this study,

384 despite differences in habitat use and body temperature between males and females. Unlike other

385 species of anoles, where larger males perch higher in the vegetation than females (Andrews,

386 1971; Delaney \& Warner, 2016; Kolbe et al., 2016), perch height seems decoupled from body 
387 size in the slender anole, which is sexually monomorphic in body size. Previous research has

388 found that ecological factors can mediate parasite infection (Wiles et al., 2000; Durden et al.,

389 2004; Biaggini et al., 2009; Leung \& Koprivnikar, 2016; Jones et al., 2019). Hence, sex-

390 differences in parasite load can often be partially explained by differences in habitat use (Gross

391 \& Fritz, 1982; Sikkel et al., 2000; Lajeunesse et al., 2004), and diet (Reimchin \& Nosil, 2001;

392 Friesen et al., 2015). Our study only identified interactions (but no main effects) between sex,

393 body temperature, and perch width on mite abundance and intensity, suggesting that habitat and

394 thermal physiology could play a sex-specific (albeit minor) role in mite infections. While our

395 study found limited evidence that sex differences in ecology impacted parasitism, we interpret

396 these results cautiously given the limited timespan and scope of the ecological component of our

397 study, and the lack of repeated ecological measures for individuals. Future research should

398 explore how sexual dimorphism in habitat use and physiological ecology could influence

399 parasitism in a sex-specific fashion in slender anoles.

400

Similar to previous work, we found evidence of a sex-specific relationship between

401 parasitic infections and energy storage (Reedy et al., 2016). First, we found that male slender

402 anoles with decreased fat stores had more mites, but there was no relationship between mite

403 infection and fat body mass in females. Multiple mechanisms could explain this relationship,

404 including 1) males with ample fat stores can invest energetically into the immune system and

405 thus have fewer mites, 2) ectoparasite infection could be energetically costly and deplete fat

406 stores or 3) an indirect correlate of lower fat body mass facilitates mite infection. Immune

407 responses incur energetic costs in a number of species (Svensson et al., 1998), including

408 congeners of the slender anole (Cox et al., 2015b), which supports the idea that energetics may

409 mediate ectoparasite infection in male slender anoles as well. Second, we found that the size of 
410 the gonads was positively associated with the number of mites in females, but not in males.

411 While gonad mass is linked to investment in precopulatory sexual selection in males (Kahrl et

412 al., 2016), gonad mass in females reflects direct energetic investment into offspring. For anoles,

413 the bilateral ovaries are a series of follicles that mature in a stepwise fashion, with alternate

414 energetic investment to the left and right ovaries (Andrews \& Rand, 1974; Cox \& Calsbeek,

415 2010). As most of the mass of the ovaries is the lipid-rich yolk of the developing follicles as well

416 as the shelled egg (Andrews \& Rand, 1974), the gonad mass of females is a direct measurement

417 of their energetic investment into offspring (Cox et al., 2010). We found that females that invest

418 heavily into reproduction can experience increased parasitism, which implies a potential

419 energetic tradeoff between reproduction and immunity. Because reproduction can be associated

420 with increased stress and circulating corticosterone in lizards (Wilson \& Wingfield, 1992; French

421 et al., 2007), our results are also consistent with reproduction-associated immunosuppression in

422 female slender anoles. Broadly, our results suggest that the role of energetics in mediating

423 parasite infection could involve sex-specific relationships among energy storage, immune

424 function, and reproduction.

425 We found that a social and sexual signal, the dewlap of anole lizards, imparts a sex-

426 specific cost of increased parasitism. Intriguingly, this cost may arise from the increased affinity

427 of mites to the dewlap itself, rather than solely from an indirect relationship of dewlap size with

428 testosterone-mediated immunosuppression. Sexual selection resulting from female choice for

429 larger male dewlaps could potentially increase parasitism and incur a survival cost to males.

430 Given that parasitism is often associated with an energetic decrement (Booth et al., 1993;

431 Scantlebury et al., 2007), investing maximally in the dewlap might ultimately limit energetic

432 resources for growth and reproduction. It is thus plausible that the fitness tradeoffs associated 
433 with expression of the dewlap could be a factor limiting both body and dewlap size in anoles, 434 even in species that are sexually monomorphic in body size.

437 Funding for this project was provided by Graduate Student Organization at Georgia Southern

438 University, the Office of Research Services and Sponsored Programs at Georgia Southern

439 University, Theodore Roosevelt Memorial Grant from the American Museum of Natural History,

440 NERC studentship grant (NE/L002485/1), a Smithsonian Pre-doctoral fellowship, Smithsonian

441 Short-term Fellowships, and the Smithsonian Tropical Research Institute. This manuscript

442 benefitted from the perspective of four anonymous reviewers.

445 C.L.C, M.L.L., and W. O. M. conceived the study. C.L.C, M.L.L., D. J. N., J.D.C., and A.K.C. 446 designed the study. C.L.C, M.L.L., D. J. N., J.D.C., A.K.C. and Z. D. collected data for the 447 study. A. A. R., D. J. N., and C.L.C wrote the first draft of the study. All authors contributed to 448 statistical analyses, figure construction, manuscript revision, and gave final approval to the 449 manuscript. 
452 Andrews R, Rand AS. 1974. Reproductive effort in anoline lizards. Ecology: 1317-1327.

Andrews RM. 1971. Structural habitat and time budget of a tropical Anolis lizard. Ecology 52: 262-270.

455

456

457

458

459

460

461

462

463

464

465

466

467

468

469

470

471

472 Copeia: 620-626.

Andrews RM. 1979. Reproductive effort of female Anolis limifrons (Sauria: Iguanidae).

Andrews RM. 1991. Population stability of a tropical lizard. Ecology 72: 1204-1217.

Andrews RM, Nichols JD. 1990. Temporal and spatial variation in survival rates of the tropical lizard Anolis limifrons. Oikos 57: 215-221.

Andrews RM, Rand AS. 1983. Limited dispersal of juvenile Anolis limifrons. Copeia: 429434.

Andrews RM, Stamps JA. 1994. Temporal variation in sexual sze dimorphism of Anolis limifrons in Panama. Copeia 1994: 613-622.

Arnold EA. 1986. Mite pockets of lizards, a possible means of reducing damage by ectoparasites. Biological Journal of the Linnean Society 29: 1-21.

Bauwens D, Strijbosch H, Stumpel AHP. 1983. The lizards Lacerta agilis and L. vivipara as hosts to larvae and nymphs of the tick Ixodes ricinus. Holarctic Ecology 6: 32-40.

Biaggini M, Berti R, Corti C. 2009. Different habitats, different pressures? Analysis of escape behavior and ectoparasite load in Podarcis sicula (Lacerteidae) populations in different agricultural habitats. Amphibia-Reptilia 30: 453-461.

Booth DT, Clayton DH, Block BA. 1993. Experimental demonstration of the energetic cost of parasitism in free-ranging hosts. Proceedings of the Royal Society B 253: 125-129. 
473 Boughton RK, Bridge ES, Schoech SJ. 2007. Energetic trade-offs between immunity and

474

475

476

477

478

479

480

481

482

483

484

485

486

487

488

489

490

491

492

493

494

495

reproduction in male Japanese quail (Coturnix coturnix). Journal of Experimental Zoology 307A: 479-487.

Brown CR, Brown MB, Rannala B. 1995. Ectoparasites reduce the long-term survival of their avian host. Proceedings of the Royal Society B 262: 313-319.

Buchholz R. 1995. Female choice, parasite load, and male ornamentation in wild turkeys. Animal Behavior 50: 929-943.

Cook EG, Murphy TG, Johnson MA. 2013a. Colorful displays signal male quality in a tropical anole lizard. Naturwissenschaften 100: 993-996.

Cook EG, Murphy TG, Johnson MA. 2013b. Colorful displays signal male quality in a tropical anole lizard. Naturwissenschaften 100: 993-996.

\section{Cox CL, Alexander S, Casement B, Chung AK, Curlis JD, Degon Z, Dubois M, Falvey C,} Graham ZA, Folfas E. 2020. Ectoparasite extinction in simplified lizard assemblages during experimental island invasion. Biology Letters 16: 20200474.

Cox CL, Hanninen AF, Reedy AM, Cox RM. 2015a. Female anoles retain responsiveness to testosterone despite the evolution of androgen-mediated sexual dimorphism. Functional ecology 29: 758-767.

Cox CL, Peaden RT, Cox RM. 2015b. The metabolic cost of mounting an immune response in male brown anoles (Anolis sagrei). Journal of Experimental Zoology in press.

Cox R, Stenquist D, Calsbeek R. 2009a. Testosterone, growth and the evolution of sexual size dimorphism. Journal of Evolutionary Biology 22: 1586-1598.

Cox RM, Calsbeek R. 2010. Severe costs of reproduction persist in Anolis lizards despite the evolution of a single-egg clutch. Evolution 64: 1321-1330. 
Cox RM, Cox CL, McGlothlin JW, Card DC, Andrew AL, Castoe TA. 2017. Hormonally mediated increases in sex-biased gene expression accompany the breakdown of betweensex genetic correlations in a sexually dimorphic lizard. The American Naturalist 189: $315-332$

Cox RM, John-Alder HB. 2005. Testosterone has opposite effects on male growth in lizards (Sceloporus spp.) with opposite patterns of sexual size dimorphism. Journal of Experimental Biology 208: 4679-4687.

Cox RM, John-Alder HB. 2007. Increased mite parasitism as a cost of testosterone in male striped plateau lizards, Sceloporus virgatus. Functional ecology 21: 327-334.

Cox RM, Parker EU, Cheney DM, Liebl AL, Martin LB, Calsbeek R. 2010. Experimental evidence for physiological costs underlying the trade-off between reproduction and survival. Functional ecology 24: 1262-1269.

Cox RM, Skelly SL, Leo A, John-Alder HB. 2005. Testosterone regulates sexually dimorphic coloration in the eastern fence lizard, Sceloporus undulatus. Copeia 2005: 597-608.

Cox RM, Stenquist DS, Henningsen JP, Calsbeek R. 2009b. Manipulating testosterone to assess links between behavior, morphology, and performance in the brown anole Anolis sagrei. Physiological and Biochemical Zoology 82: 686-698.

Cox RM, Zilberman V, John-Alder HB. 2008. Testosterone stimulates the expression of a social color signal in yarrow's spiny lizard, Sceloporus jarrovii. Journal of Experimental Zoology Part A: Ecological Genetics and Physiology 309: 505-514.

Curlis JD, Davis RW, Zetkulic E, Cox CL. 2017. Condition dependence of shared traits differs between sympatric Anolis lizards. Journal of Experimental Zoology Part A: Ecological and Integrative Physiology 327: 110-118. 
Curtis JL, Baird TA. 2008. Within-population variation in free-living adult and ectoparasitic larval Trombiculid mites on collared lizards. Herpetologica 64: 189-199.

Dale J, Dey CJ, Delhey K, Kempenaers B, Valcu M. 2015. The effects of life history and sexual selection on male and female plumage coloration. Nature 527: 367-370.

Delaney DM, Warner DA. 2016. Age-and sex-specific variations in microhabitat and macrohabitat use in a territorial lizard. Behavioral Ecology and Sociobiology 70: 981991.

Derickson WK. 1976. Lipid storage and utilization in reptiles. American Zoologist 16: 711-723.

Diaz-Real J, Serrano D, Pérez-Tris J, Fernández-González S, Bermejo A, Calleja JA, De la Puente J, De Palacio D, Martínez JL, Moreno-Opo R. 2014. Repeatability of feather mite prevalence and intensity in passerine birds. PLOS ONE 9: e107341.

Doucet SM, Montgomerie R. 2003. Multiple sexual ornaments in satin bowerbirds: ultraviolet plumage and bowers signal different aspects of male quality. Behavioral Ecology 14: 503-509.

Dudek K, Skorka P, Sajkowska ZA, Ekner-Grzyb A, Dudek M, Tryjanoski P. 2016. Distribution pattern and number of ticks on lizards. Ticks and tick-borne diseases 7: 172179.

Durden LA, Ellis BA, Banks CW, Crowe JD, Oliver Jr. JH. 2004. Ectoparasites of gray squirrels in two different habitats and screening of selected ectoparasites for Bartonellae. Journal of Parasitology 90: 485-489.

Dzialowski EM. 2005. Use of operative temperature and standard operative temperature models in thermal biology. Journal of thermal biology 30: 317-334. 
Edworthy AB, Langmore NE, Heinsohn R. 2019. Native fly parasites are the principal cause of nestling mortality in endangered Tasmanian pardalotes. Animal Conservation 22: 96103.

Fernald RD. 1976. The effect of testosterone on the behavior and coloration of adult male cichlid fish (Haplochromis burtoni, Gunther). Hormone Research 7: 172-178.

Fichet-Calvet E, Wang J, Jomaa I, Ismail RB, Ashford R. 2003. Patterns of the tapeworm Raillietina trapezoides infection in the fat sand rat Psammomys obesus in Tunisia: season, climatic conditions, host age and crowding effects. Parasitology 126: 481-492.

Fisher R. 1930. The Genetical Theory of Natural Selection: Clarendon Press, Oxford.

Folstad I, Karter AJ. 1992. Parasites, bright males, and the immunocompetence handicap. American Naturalist: 603-622.

French SS, McLemore R, Vernon B, Johnston GI, Moore MC. 2007. Corticosterone modulation of reproductive and immune systems trade-offs in female tree lizards: longterm corticosterone manipulations via injectable gelling material. Journal of Experimental Biology 210: 2859-2865.

Friesen OC, Roth JD, Graham LC. 2015. Sex-biased parasitism in monogamous arctic foxes is driven by diet. Journal of Mammalogy 96: 417-424.

Goldberg SR, Bursey CR. 1991. Integumental lesions caused by ectoparasites in a wild population of the side-blotched lizard (Uta stansburiana). Journal of Wildlife Diseases 27: $68-73$.

Goldberg SR, Holshuh H. 1992. Ectoparasite-induced lesions in mite pockets of the Yarrow's spiny lizard, Sceloporus jarrovii (Phrynosomatidae). Journal of Wildlife Diseases 28: $537-541$ 
Gross WW, Fritz RS. 1982. Differential stratification, movement and parasitism of sexes of the bagworm, Thyridopteryx ephemeraeformis on redcedar. Ecological Entomology 7: 149154.

Hamilton WD, Zuk M. 1982. Heritable true fitness and bright birds: a role for parasites? Science 218: 384-387.

Harrison A, Poe S. 2012. Evolution of an ornament, the dewlap, in females of the lizard genus Anolis. Biological Journal of the Linnean Society 106: 191-201.

Hawlena H, Abramsky Z, Krasnov BR. 2006. Ectoparasites and age-dependent survival in a desert rodent. Oecologia 148: 30-39.

Heredia VJ, Vicente N, Robles C, Halloy M. 2014. Mites in the neotropical lizard Liolaemus pacha (Iguania: Liolaemidae): Relation to body size, sex and season. South american journal of herpetology 9: 14-19.

Hoefler CD, Persons MH, Rypstra AL. 2007. Consequences of complex signaling: predator detection of multimodal cues. Behavioral Ecology 18: 236-240.

Huyghe K, Van Oystaeyen A, Pasmans F, Tadić Z, Vanhooydonck B, Van Damme R. 2010. Seasonal changes in parasite load and a cellular immune response in a colour polymorphic lizard. Oecologia 163: 867-874.

Johnson N, Lymburner A, Blouin-Demers G. 2019. The impact of ectoparasitism on thermoregulation in Yarrow's Spiny Lizards (Sceloporus jarrovii). Canadian Journal of Zoology 97: 1004-1012.

Jones H, Pekins P, Kantar L, Sidor I, Ellingwood D, Lichtenwalner A, O'Neal M. 2019. Mortality assessment of moose (Alces alces) calves during successive years of winter tick 
(Dermacentor albipictus) epizootics in New Hampshire and Maine (USA). Canadian Journal of Zoology 97: 22-30.

Jovani R, Serrano D. 2001. Feather mites (Astigmata) avoid moulting wing feathers of passerine birds. Animal Behaviour 62: 723-727.

Jovani R, Serrano D. 2004. Fine-tuned distribution of feather mites (Astigmata) on the wing of birds: the case of blackcaps Sylvia atricapilla. Journal of Avian Biology 35: 16-20.

Jovani R, Serrano D, Frias O, Blanco G. 2006. Shift in feather mite distribution during the molt of passerines: the case of barn swallows (Hirundo rustica). Canadian Journal of Zoology 84: 729-735.

Kahrl AF, Cox CL, Cox RM. 2016. Correlated evolution between targets of pre-and postcopulatory sexual selection across squamate reptiles. Ecology and evolution 6: 64526459.

Klukowski M. 2004. Seasonal changes in abundance of host-seeking chiggers (Acari: Trombiculidae) and infestations on fence lizards, Sceloporus undulatus. Journal of Herpetology 38: 141-144.

Kohler G, Sunyer J. 2008. Two new species of anoles formerly referred to as Anolis limifrons (Squamata: Polychrotidae). Herpetologica 64: 92-108.

Kolbe JJ, Battles AC, Avilés-Rodríguez KJ. 2016. City slickers: poor performance does not deter Anolis lizards from using artificial substrates in human-modified habitats. Functional Ecology 30: 1418-1429.

Lajeunesse MJ, Forbes MR, Smith BP. 2004. Species and sex-biases in ectoparasitism of dragonflies by mites. Oikos 106: 501-508. 
Lamarre V, Legagneux P, Franke A, Casajus N, Currie DC, Berteaux D, Bety J. 2018. Precipitation and ectoparasitism reduce reproductive success in an arctic-nesting top predator. Scientific Reports 8: 8530.

Leung TLF, Koprivnikar J. 2016. Nematode parasite diversity in birds: the role of host ecology, life history, and migration. Journal of Animal Ecology 85: 1471-1480.

Lindsay WR, Webster MS, Schwabl H. 2011. Sexually selected male plumage color is testosterone dependent in a tropical passerine bird, the red-backed fairy-wren (Malurus melanocephalus). PLoS One 6: e26067.

Lovern MB, Holmes MM, Fuller CO, Wade J. 2004. Effects of testosterone on the development of neuromuscular systems and their target tissues involved in courtship and copulation in green anoles (Anolis carolinensis). Hormones and Behavior 45: 295-305.

Lovern MB, McNabb FA, Jenssen TA. 2001. Developmental effects of testosterone on behavior in male and female green anoles (Anolis carolinensis). Hormones and Behavior 39: 131-143.

Lumbad AS, Vredevoe LK, Taylor EN. 2011. Season and sex of host affect intensities of ectoparasites in western fence lizards (Sceloporus occidentalis) on the central coast of California. The Southwestern Naturalist 56: 369-377.

Moseley MA, Cox CL, Streicher JW, Roelke CE, Chippindale PT. 2015. Phylogeography and lineage-specific patterns of genetic diversity and molecular evolution in a group of North American skinks. Biological Journal of the Linnean Society 116: 819-833.

Muehlenbein MP, Bribiescas RG. 2005. Testosterone-mediated immune functions and male life histories. American Journal of Human Biology 17: 527-558. 
Olsson M, Wapstra E, Madsen T, Silverin B. 2000. Testosterone, ticks and travels: a test of the immunocompetence handicap hypothesis in free-ranging male sand lizards. Proceedings of the Royal Society B 267: 2339-2343.

Perez-Orella C, Schulte-Hostedde AI. 2005. Effects of sex and body size on ectoparasite loads in the northern flying squirrel. Canadian Journal of Zoology 83: 1381-1385.

Poiani A, Goldsmith AR, Evans MR. 2000. Ectoparasites of house sparrows (Passer domesticus): an experimental test of the immunocompetence handicap hypothesis and a new model. Behavioral Ecology and Sociobiology 47: 230-242.

Rand AS, Myers CW. 1990. The herpetofauna of Barro Colorado Island, Panama: an ecological summary. Four neotropical rainforests: 386-409.

\section{Rantala MJ, Moore FR, Skrinda I, Krama T, Kivleniece I, Kecko S, Krams I. 2012.} Evidence for the stress-linked immunocompetence handicap hypothesis in humans. Nature Communications 3: 694.

Reedy AM, Cox CL, Chung AK, Evans WJ, Cox RM. 2016. Both sexes suffer increased parasitism and reduced energy storage as costs of reproduction in the brown anole, Anolis sagrei. Biological Journal of the Linnean Society 117: 516-527.

Reimchin TE, Nosil P. 2001. Ecological causes of sex-biased parasitism in the Biological Journal of the Linnean Society 73: 51-63.

Richner H, Oppliger A, Christe P. 1993. Effect of an ectoparasite on reproduction in great tits. Journal of Animal Ecology 62: 703-710.

\section{Rocha CFD, Cunha-Barros M, Menezes VA, Fontes AF, Vrcibradic D, Van Sluys M. 2008.}

Pattens of infestation by the trombiculid mite Eutrombicula alfreddguesi in four sympatric lizard species (genus Tropidurus) in northeastern Brazil. Parasite 15: 131-136. 
Ryan MJ, Tuttle MD, Rand AS. 1982. Bat predation and sexual advertisement in a neotropical anuran. The American Naturalist 1982: 136-139.

Salvador A, Veiga JP, Martin J, Lopez P, Abelenda A, Puerta M. 1996. The cost of producing a sexual signal: testosterone increases the susceptibility of male lizards to ectoparasite infection. Behavior Ecology 7: 145-150.

Scantlebury M, Waterman JM, Hillegass M, Speakman JR, Bennett NC. 2007. Energetic costs of parasitism in the Cape ground squirrel Xerus inauris. Proceedings of the Royal Society B 274: 2169-2177.

Schaefer HM, Ruxton GD. 2015. Signal diversity, sexual selection, and speciation. Annual Review of Ecology, Evolution, and Systematics 46: 573-592.

Schall JJ. 1983. Lizard malaria: cost to vertebrate host's reproductive success. Parasitology 87: $1-6$.

Schneider CA, Rasbabd WS, Eliceiri KW. 2012. NIH Image to ImageJ: 25 years of image analysis. Nature methods 9: 671-675.

\section{Seddon N, Botero CA, Tobias JA, Dunn PO, MacGregor HA, Rubenstein DR, Uy JAC,} Wier JT, Whittingham LA, Safran RJ. 2013. Sexual selection accelerates signal evolution during speciation in birds. Proceedings of the Royal Society B 280: 20131065.

Sikkel PC, Fuller CA, Hunte W. 2000. Habitat/sex differences in time at cleaning stations and ectoparasite loads in a Carribean reef fish. Marine Ecology Progress Series 193: 191199.

Siva-Jothy MT. 2000. A mechanistic link between parasite resistance and expression of a sexually selected trait in a damselfly. Proceedings of the Royal Society B 267: 25232527. 
676 Smith GR. 1996. Mites on striped plateua lizards (Sceloporus virgatus: Phrynosomatidae):

677

678

679

680

681

682

683

684

685

686

687

688

689

690

691

692

693

694

695

696

697

698

abundance, distribution, and effects on host growth. Herpetological Natural History 4:

175-180.

Spears RE, Durden LA, Hagan DV. 1999. Ectoparasites of Brazilian free-tailed bats with emphasis on anatomical site preferences for Chiroptonyssus robustipes (Acari: Macronyssidae). Journal of Medical Entomology 36: 481-485.

Stapley J, Wordley C, Slate J. 2011. No evidence of genetic differentiation between anoles with different dewlap color patterns. J Hered 102: 118-124.

Svensson E, Raberg L, Koch C, Hasselquist D. 1998. Energetic stress, immunosuppression and the costs of an antibody response. Functional Ecology 12: 912-919.

Symonds MRE, Elgar MA. 2007. The evolution of pheremone diversity. Trends in Ecology and Evolution 23: 220-228.

Talbot JJ. 1979. Time Budget, Niche Overlap, Inter-and Intraspecific Aggression in Anolis humlis and A. limifrons from Costa Rica. Copeia: 472-481.

Taskinen J, Kortet R. 2002. Dead and alive parasites: sexual ornaments signal resistance in the male fish, Rutilus rutilus. Evolutionary Ecology Research 4: 919-929.

Telford SR. 1974. The malarial parasites of Anolis species (Sauria: Iguanidae) in Panama. International Journal of Parasitology 4: 91-102.

Todd AC. 2008. Using testis size to predict the mating systems of New Zealand geckos. New Zealand Journal of Zoology 35: 103-114.

Watson CM, Degon Z, Krogman W, Cox CL. 2019. Evolutionary and ecological forces underlying ontogenetic loss of decoy coloration. Biological Journal of the Linnean Society 128: 138-148. 
Werman SD. 1983. Population dynamics of the lizard mite, Hirstiella pyriformis (Acari: Pterygosomatidae) on the chuckwalla, Sauromalus obesus (Sauria: Iguanidae). The Journal of parasitology: 381-386.

Wiles PR, Cameron J, Behnke JM, Hartley IR, Gilbert FS, McGregor PK. 2000. Season and ambient air temperature influence the distribution of mites (Proctophyllodes stylifer) across the wings of blue tits (Parus caeruleus). Canadian Journal of Zoology 78: 13971497.

Wilson BS, Wingfield JC. 1992. Correlation between female reproductive condition and plasma corticosterone in the lizard Uta stansburiana. Copeia: 691-697.

Wright S, Wikel S, Wrenn W. 1988. Host immune responsiveness to the chigger, Eutrombicula cinnabaris. Annals of Tropical Medicine \& Parasitology 82: 283-293.

Zippel KC, PowELL R, Parmerlee JS, Monks S, Lathrop A, Smith DD. 1996. The distribution of larval Eutrombicula alfreddugesi (Acari: Trombiculidae) infesting Anolis lizards (Lacertilia: Polychrotidae) from different habitats on Hispaniola. Caribbean Journal of Science 32: 43-49.

\section{SHARED DATA}

All data will be archived upon acceptance. 
717 Table 1. Ecological correlates of mite infection. Results are from generalized linear models with 718 a log link function to a Poisson distribution (mite abundance and intensity) and nominal logistic 719 regression (mite prevalence). Statistically significant results are in bolded italics.

720

\begin{tabular}{cccccccc}
\hline & & \multicolumn{3}{c}{ Habitat } & \multicolumn{3}{c}{$\begin{array}{c}\text { Sex by Habitat } \\
\text { Variable }\end{array}$} \\
\cline { 3 - 8 } & d.f. & $\chi^{2}$ & $P$ & $\chi^{2}$ & $P$ & $\chi^{2}$ & $P$ \\
\hline Mite Abundance & & & & & & & \\
Perch Height & 484 & 461.83 & $<\mathbf{0 . 0 0 0 1}$ & 0.06 & 0.8099 & 0.01 & 0.9315 \\
Perch Diameter & 464 & 498.36 & $\mathbf{< 0 . 0 0 0 1}$ & 2.49 & 0.1148 & 2.13 & 0.1448 \\
Body temperature & 502 & 496.71 & $\mathbf{< 0 . 0 0 0 1}$ & 1.51 & 0.2197 & 20.83 & $<\mathbf{0 . 0 0 0 1}$ \\
Mite Intensity & & & & & & & \\
Perch Height & 342 & 240.17 & $\mathbf{< 0 . 0 0 0 1}$ & 1.86 & 0.1728 & 0.57 & 0.4496 \\
Perch Diameter & 328 & 252.61 & $\mathbf{< 0 . 0 0 0 1}$ & 1 & 0.3168 & 4.314 & $\mathbf{0 . 0 3 7 8}$ \\
Body temperature & 358 & 271.62 & $\mathbf{< 0 . 0 0 0 1}$ & 0.02 & 0.8808 & 12.62 & $\mathbf{0 . 0 0 0 4}$ \\
Mite Prevalence & & & & & & & \\
Perch Height & 488 & 12.65 & $\mathbf{0 . 0 0 0 4}$ & 0.46 & 0.5002 & 0.23 & 0.6354 \\
Perch Diameter & 468 & 14.89 & $\mathbf{0 . 0 0 0 1}$ & 0.3 & 0.5846 & 0.26 & 0.6097 \\
Body temperature & 506 & 13.15 & $\mathbf{0 . 0 0 0 3}$ & 1.1 & 0.2965 & 0.71 & 0.3984 \\
\hline
\end{tabular}

721

722

723

724

725

726 
727 Table 2. Body size (mass and SVL) correlates of ectoparasite infection. Results are from

728 generalized linear models with a log link function to a Poisson distribution (mite abundance and

729 intensity) and nominal logistic regression (mite prevalence). SVL=snout-vent length. Statistically

730 significant results are in bolded italics.

\begin{tabular}{|c|c|c|c|c|c|c|c|}
\hline & \multicolumn{3}{|c|}{ Sex } & \multicolumn{2}{|l|}{ Size } & \multicolumn{2}{|c|}{ Size by Sex } \\
\hline & d.f. & $\chi^{2}$ & $P$ & $\chi^{2}$ & $P$ & $\chi^{2}$ & $P$ \\
\hline \multicolumn{8}{|l|}{ Mite Abundance } \\
\hline SVL & 511 & 363.01 & $<0.0001$ & 148.17 & $<0.0001$ & 20.88 & $<0.0001$ \\
\hline Mass & 511 & 481.42 & $<0.0001$ & 196.44 & $<0.0001$ & 26.63 & $<0.0001$ \\
\hline \multicolumn{8}{|l|}{ Mite Intensity } \\
\hline SVL & 362 & 228.35 & $<0.0001$ & 26.19 & $<0.0001$ & 11.84 & 0.0006 \\
\hline Mass & 362 & 268.12 & $<0.0001$ & 29.52 & $<0.0001$ & 17.27 & $<0.0001$ \\
\hline \multicolumn{8}{|l|}{ Mite Prevalence } \\
\hline SVL & 515 & 11.34 & 0.0008 & 21.89 & $<0.0001$ & 2.79 & 0.0946 \\
\hline Mass & 515 & 18.41 & $<0.0001$ & 30.7 & $<0.0001$ & 3.21 & 0.0733 \\
\hline \multicolumn{8}{|c|}{ Dewlap Mite Abundance } \\
\hline SVL & 511 & 301.70 & $<0.0001$ & 61.42 & $<0.0001$ & 6.10 & 0.0136 \\
\hline Mass & 511 & 373.03 & $<0.0001$ & 80.01 & $<0.0001$ & 9.46 & 0.0021 \\
\hline \multicolumn{8}{|c|}{ Dewlap Mite Intensity } \\
\hline SVL & 302 & 83.85 & $<0.0001$ & 4.94 & 0.0263 & 1.49 & 0.2228 \\
\hline Mass & 302 & 93.87 & $<0.0001$ & 7.88 & 0.0050 & 2.77 & 0.0733 \\
\hline \multicolumn{8}{|c|}{ Dewlap Mite Prevalence } \\
\hline SVL & 515 & 51.18 & $<0.0001$ & 28.17 & $<0.0001$ & 7.45 & 0.0063 \\
\hline Mass & 515 & 67.69 & $<0.0001$ & 34.43 & $<0.0001$ & 10.30 & 0.0013 \\
\hline \multicolumn{8}{|c|}{ Axillary Mite Abundance } \\
\hline SVL & 511 & 66.55 & $<0.0001$ & 7.55 & 0.0063 & 0.82 & 0.3645 \\
\hline Mass & 511 & 55.64 & $<0.0001$ & 5.01 & 0.0252 & 0.05 & 0.8193 \\
\hline \multicolumn{8}{|c|}{ Axillary Mite Intensity } \\
\hline SVL & 101 & 2.51 & 0.1132 & 3.87 & 0.0492 & 1.52 & 0.2181 \\
\hline Mass & 101 & 1.35 & 0.2455 & 0.70 & 0.4033 & 0.26 & 0.6134 \\
\hline \multicolumn{8}{|c|}{ Axillary Mite Prevalence } \\
\hline SVL & 515 & 28.51 & $<0.0001$ & 0.32 & 0.5701 & 0.38 & 0.5369 \\
\hline Mass & 515 & 25.37 & $<0.0001$ & 1.38 & 0.2406 & 0.28 & 0.5989 \\
\hline \multicolumn{8}{|c|}{ Inguinal Mite Abundance } \\
\hline SVL & 511 & 56.04 & $<0.0001$ & 0.01 & 0.9053 & 0.11 & 0.7356 \\
\hline Mass & 511 & 53.40 & $<0.0001$ & 0.13 & 0.7173 & 0.54 & 0.4639 \\
\hline \multicolumn{8}{|c|}{ Inguinal Mite Intensity } \\
\hline SVL & 106 & 4.34 & 0.0373 & 0.23 & 0.6299 & 0.12 & 0.7324 \\
\hline Mass & 106 & 4.31 & 0.0379 & 0.01 & 0.9408 & 0.63 & 0.4280 \\
\hline
\end{tabular}




\begin{tabular}{cccccccc} 
Inguinal Mite Prevalence & & & & & & & \\
SVL & 515 & 19.61 & $<\mathbf{0 . 0 0 0 1}$ & 0.17 & 0.5783 & 0.01 & 0.9342 \\
Mass & 515 & 19.61 & $<\mathbf{0 . 0 0 0 1}$ & 0.17 & 0.6791 & 0.01 & 0.9332 \\
\hline
\end{tabular}

731

732

733

734 
735 Table 3. Dewlap size correlates of ectoparasite infection. Results are from generalized linear

736 models with a log link function to a Poisson distribution (mite abundance and intensity) and

737 nominal logistic regression (mite prevalence) for three different body regions. Males and females

738 were analyzed separately because of non-overlapping dewlap size. SVL=snout-vent length. Both

739 dewlap area and SVL were log-transformed prior to analyses. Statistically significant results are

740 in bolded italics.

741

\begin{tabular}{|c|c|c|c|c|c|c|c|}
\hline & \multirow[b]{2}{*}{ d.f. } & \multicolumn{2}{|c|}{ Dewlap Area } & \multicolumn{2}{|c|}{ SVL } & \multicolumn{2}{|c|}{$\begin{array}{c}\text { SVL by Dewlap } \\
\text { Area }\end{array}$} \\
\hline & & $\chi^{2}$ & $P$ & $\chi^{2}$ & $P$ & $\chi^{2}$ & $P$ \\
\hline \multicolumn{8}{|c|}{ Mite Abundance } \\
\hline Males & 276 & 44.74 & $<0.0001$ & 67.57 & $<0.0001$ & 44.99 & $<0.0001$ \\
\hline Females & 230 & 0.14 & 0.7101 & 14.68 & $<0.0001$ & 0.14 & 0.7094 \\
\hline \multicolumn{8}{|c|}{ Total Intensity } \\
\hline Males & 212 & 29.87 & $<0.0001$ & 28.89 & $<0.0001$ & 29.53 & $<0.0001$ \\
\hline Females & 144 & 0.21 & 0.6475 & 0.01 & 0.9349 & 0.17 & 0.6789 \\
\hline \multicolumn{8}{|c|}{ Total Prevalence } \\
\hline Males & 276 & 0.20 & 0.6542 & 7.53 & 0.0061 & 0.20 & 0.6537 \\
\hline Females & 227 & 0.07 & 0.7873 & 4.83 & 0.0280 & 0.09 & 0.7603 \\
\hline \multicolumn{8}{|c|}{ Dewlap Mite Abundance } \\
\hline Males & 276 & 25.38 & $<0.0001$ & 32.69 & $<0.0001$ & 25.43 & $<0.0001$ \\
\hline Females & 230 & 0.70 & 0.4041 & 4.95 & 0.0260 & 0.67 & 0.4132 \\
\hline \multicolumn{8}{|c|}{ Dewlap Mite Intensity } \\
\hline Males & 203 & 1.40 & 0.2380 & 6.03 & 0.0140 & 1.43 & 0.2312 \\
\hline Females & 94 & 1.12 & 0.2895 & 0.05 & 0.8293 & 1.08 & 0.2973 \\
\hline \multicolumn{8}{|c|}{ Dewlap Mite Prevalence } \\
\hline Males & 276 & 3.44 & 0.0637 & 4.69 & 0.0304 & 3.38 & 0.0660 \\
\hline Females & 227 & 0.01 & 0.9925 & 2.46 & 0.1168 & 0.01 & 0.9895 \\
\hline \multicolumn{8}{|c|}{ Axillary Mite Abundance } \\
\hline Males & 276 & 1.91 & 0.1666 & 10.75 & 0.0010 & 1.68 & 0.1951 \\
\hline Females & 229 & 0.06 & 0.8138 & 3.30 & 0.0694 & 0.06 & 0.8001 \\
\hline \multicolumn{8}{|c|}{ Axillary Mite Intensity } \\
\hline Males & 29 & 0.07 & 0.7955 & 5.49 & 0.0191 & 0.17 & 0.6844 \\
\hline Females & 50 & 0.15 & 0.7019 & 0.36 & 0.5482 & 0.16 & 0.6904 \\
\hline \multicolumn{8}{|c|}{ Axillary Mite Prevalence } \\
\hline Males & 276 & 3.76 & 0.0482 & 0.70 & 0.4045 & 3.84 & 0.0460 \\
\hline Females & 227 & 0.02 & 0.8867 & 0.90 & 0.3422 & 0.02 & 0.8889 \\
\hline
\end{tabular}




\begin{tabular}{|c|c|c|c|c|c|c|c|}
\hline & \multirow[b]{2}{*}{ d.f. } & \multicolumn{2}{|c|}{ Dewlap Area } & \multicolumn{2}{|c|}{ SVL } & \multicolumn{2}{|c|}{$\begin{array}{c}\text { SVL by Dewlap } \\
\text { Area }\end{array}$} \\
\hline & & $\chi^{2}$ & $P$ & $\chi^{2}$ & $P$ & $\chi^{2}$ & $P$ \\
\hline \multicolumn{8}{|c|}{ Inguinal Mite Abundance } \\
\hline Males & 276 & 0.34 & 0.5580 & 0.35 & 0.5546 & 0.33 & 0.5642 \\
\hline Females & 229 & 2.00 & 0.1573 & 1.50 & 0.2208 & 1.91 & 0.1660 \\
\hline \multicolumn{8}{|c|}{ Inguinal Mite Intensity } \\
\hline Males & 35 & 2.21 & 0.1369 & 0.05 & 0.8337 & 2.32 & 0.1281 \\
\hline Females & 67 & 0.54 & 0.4633 & 1.11 & 0.2922 & 0.54 & 0.4636 \\
\hline \multicolumn{8}{|c|}{ Inguinal Mite Prevalence } \\
\hline Males & 275 & 0.60 & 0.4398 & 0.01 & 0.9318 & 0.64 & 0.4240 \\
\hline Females & 227 & 0.45 & 0.5040 & 0.01 & 0.9069 & 0.41 & 0.5204 \\
\hline
\end{tabular}

742

743 
744 Table 4. Energetic correlates of ectoparasite infection. Results are from generalized linear

745 models with a log link function to a Poisson distribution for mite abundance. Males and females

746 were also analyzed separately because of divergent organ masses. SVL=snout-vent length.

747 Statistically significant results are in bolded italics.

\begin{tabular}{|c|c|c|c|c|c|c|c|c|c|}
\hline & \multicolumn{3}{|c|}{ Sex } & \multicolumn{2}{|c|}{ Organ Mass } & \multicolumn{2}{|c|}{ Body Mass } & \multicolumn{2}{|c|}{ Sex by Organ Mass } \\
\hline & d.f. & $\chi^{2}$ & $P$ & $\chi^{2}$ & $P$ & $\chi^{2}$ & $P$ & $\chi^{2}$ & $P$ \\
\hline \multicolumn{10}{|c|}{ Mite abundance } \\
\hline \multicolumn{10}{|l|}{ Fat Body } \\
\hline Both Sexes & 94 & 31.64 & $<0.0001$ & 7.78 & 0.0053 & 53.49 & $<0.0001$ & 10.56 & 0.0011 \\
\hline Males & 64 & - & - & 33.99 & $<0.0001$ & 52.34 & $<0.0001$ & - & - \\
\hline Females & 29 & - & - & 0.19 & 0.6602 & 4.45 & 0.0349 & - & - \\
\hline \multicolumn{10}{|l|}{ Liver } \\
\hline Both sexes & 97 & 42.54 & $<0.0001$ & 0.02 & 0.8829 & 31.25 & $<0.0001$ & 1.1 & 0.22994 \\
\hline Males & 64 & - & - & 1.38 & 0.2398 & 35.63 & $<0.0001$ & - & - \\
\hline Females & 31 & - & - & 2.37 & 0.1236 & 0.79 & 0.3732 & - & - \\
\hline \multicolumn{10}{|l|}{ Gonads } \\
\hline Both Sexes & - & - & - & - & - & - & - & - & - \\
\hline Males & 33 & - & - & 0.121 & 0.7275 & 1.86 & 0.1726 & - & - \\
\hline Females & 31 & - & - & 18.51 & $<0.0001$ & 0.02 & 0.9 & - & - \\
\hline \multicolumn{10}{|c|}{ Mite Intensity } \\
\hline \multicolumn{10}{|l|}{ Fat Body } \\
\hline Both Sexes & 65 & 2.18 & 0.1396 & 5.50 & 0.0190 & 37.58 & $<0.0001$ & 3.95 & 0.0468 \\
\hline Males & 45 & - & - & 13.91 & 0.0002 & 19.58 & $<0.0001$ & - & - \\
\hline Females & 19 & - & - & 0.14 & 0.7109 & 19.23 & $<0.0001$ & - & - \\
\hline \multicolumn{10}{|l|}{ Liver } \\
\hline Both sexes & 67 & 8.64 & 0.0033 & 0.44 & 0.5075 & 18.06 & $<0.0001$ & 11.33 & 0.0008 \\
\hline Males & 46 & - & - & 4.40 & 0.0360 & 19.07 & $<0.0001$ & - & - \\
\hline Females & 20 & - & - & 8.43 & 0.0037 & 1.11 & 0.2923 & - & - \\
\hline \multicolumn{10}{|l|}{ Gonads } \\
\hline Both Sexes & - & - & - & - & - & - & - & - & - \\
\hline Males & 20 & - & - & 8.65 & 0.0033 & 1.39 & 0.2387 & - & - \\
\hline Females & 20 & - & - & 14.54 & 0.0001 & 0.94 & 0.3329 & - & - \\
\hline \multicolumn{10}{|c|}{ Mite Prevalence } \\
\hline \multicolumn{10}{|l|}{ Fat Body } \\
\hline Both Sexes & 84 & 0.14 & 0.7079 & 0.48 & 0.4893 & 0.26 & 0.6134 & 0.08 & 0.7835 \\
\hline Males & 56 & - & - & 1.37 & 0.2426 & 2.13 & 0.1441 & - & - \\
\hline $\begin{array}{l}\text { Females } \\
\text { Liver }\end{array}$ & 27 & - & - & 0.04 & 0.8462 & 0.98 & 0.3213 & - & - \\
\hline
\end{tabular}




\begin{tabular}{lccccccccc} 
Both sexes & 97 & 0.45 & 0.5005 & 0.66 & 0.4162 & 0.03 & 0.8689 & 2.38 & 0.1231 \\
Males & 65 & - & - & 0.75 & 0.3881 & 0.21 & 0.3881 & - & - \\
Females & 31 & - & - & 0.05 & 0.8306 & 0.54 & 0.4620 & - & - \\
Gonads & & & & & & & & & \\
Both Sexes & - & - & - & - & - & - & - & - & - \\
Males & 34 & - & - & 1.84 & 0.1749 & 0.01 & 0.9835 & - & - \\
Females & 31 & - & - & 1.30 & 0.2543 & 1.67 & 0.1961 & - & - \\
\hline
\end{tabular}



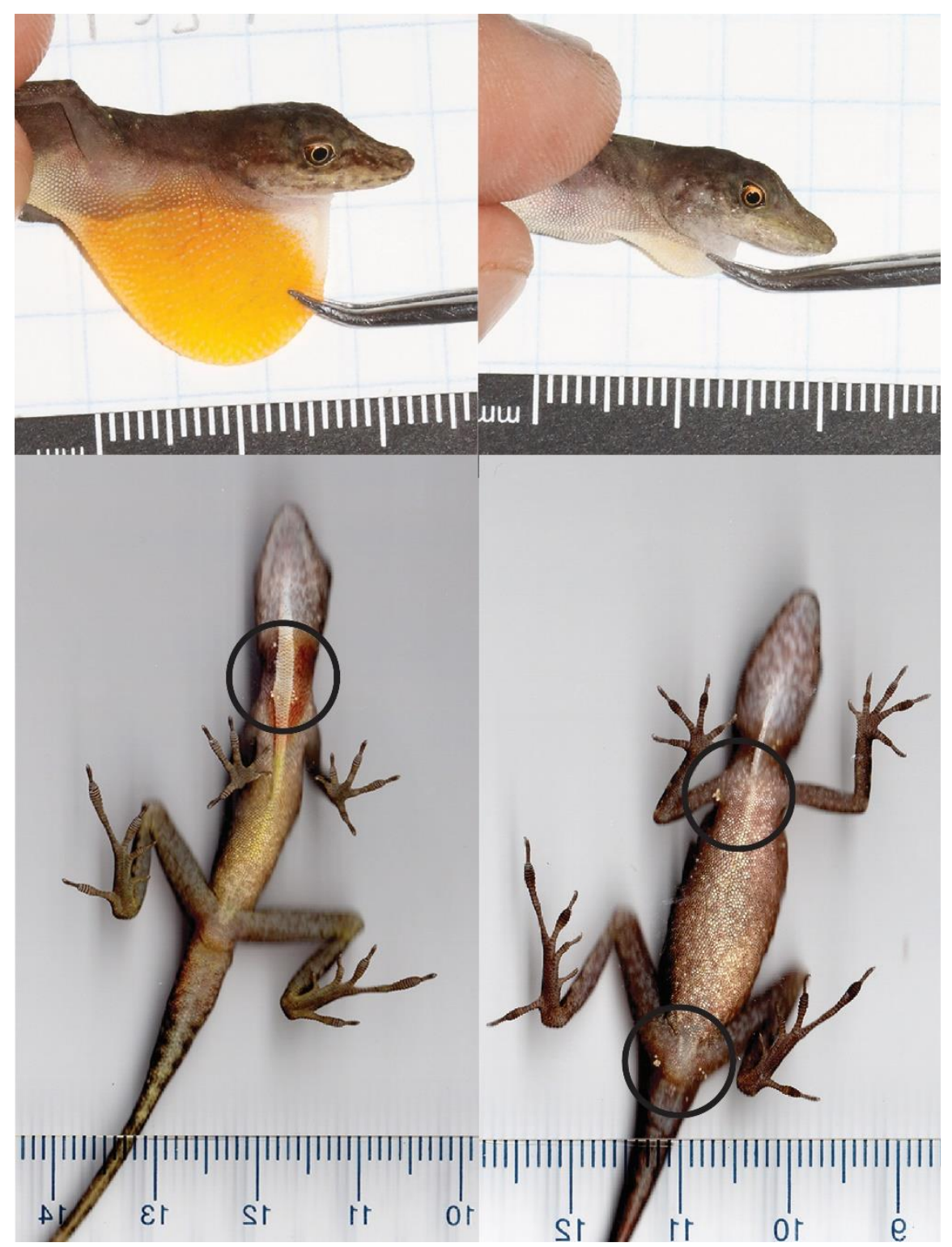

752 Figure 1. Male (left) and female (right) Panamanian slender anoles with mite infections. Male 753 anoles (top left) have larger dewlaps than females (top right). Mites can infect the dewlap (male, 754 bottom left) as well as the inguinal and axillary regions (female, bottom right). 

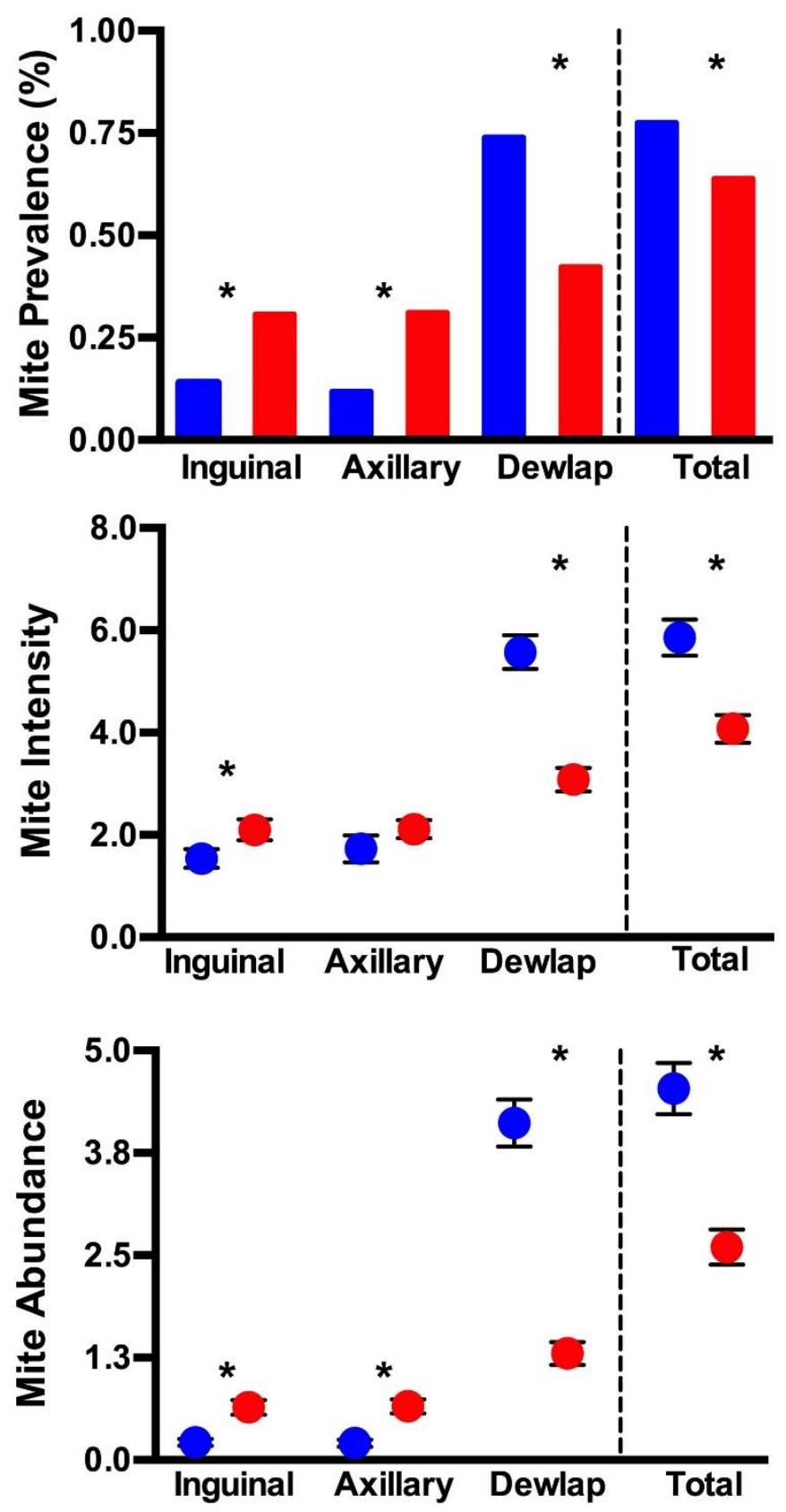

756 Figure 2. Mite prevalence (top), intensity (middle) and abundance (bottom) of male (blue) and

757 female (red) Panamanian slender anoles across three different body regions. Symbols for mite

758 abundance and intensity are means \pm S.E.M. Males had greater prevalence, intensity, and

759 abundance of mites than females when summed across body regions. Females had greater

760 prevalence, intensity, and abundance of mites than males in the inguinal and axillary regions. 
761 However, males had far greater prevalence, intensity, and abundance of mites on their dewlaps 762 than females.

763 

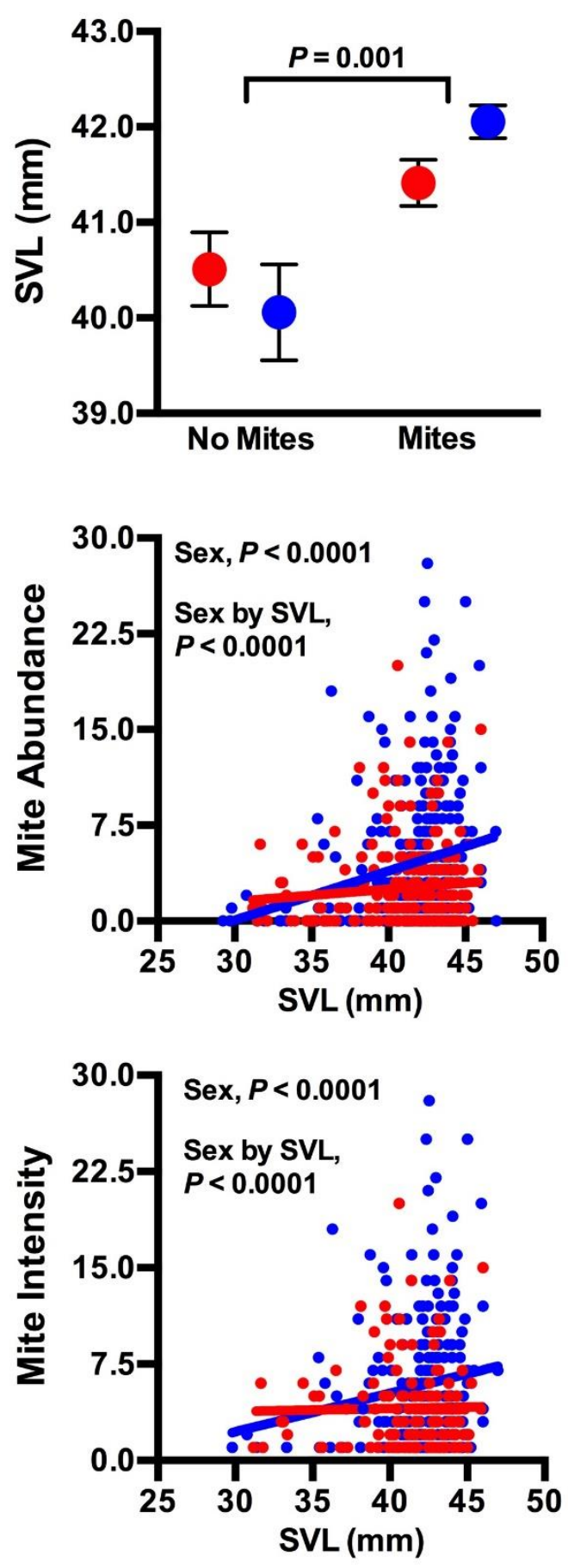

767 Figure 3. Relationship between body size and mite prevalence (top), intensity (middle) and 768 abundance (bottom) of male (blue) and female (red) Panamanian slender anoles. Symbols (top) 
769 are means \pm S.E.M. Lines (middle and bottom) are best fit-lines from ordinary least-square

770 regression analyses. Both males and females with mites were larger than those without mites

771 (top). Mite abundance (middle) and intensity of (bottom) increased with body size for male but

772 not female anoles.

773

774 

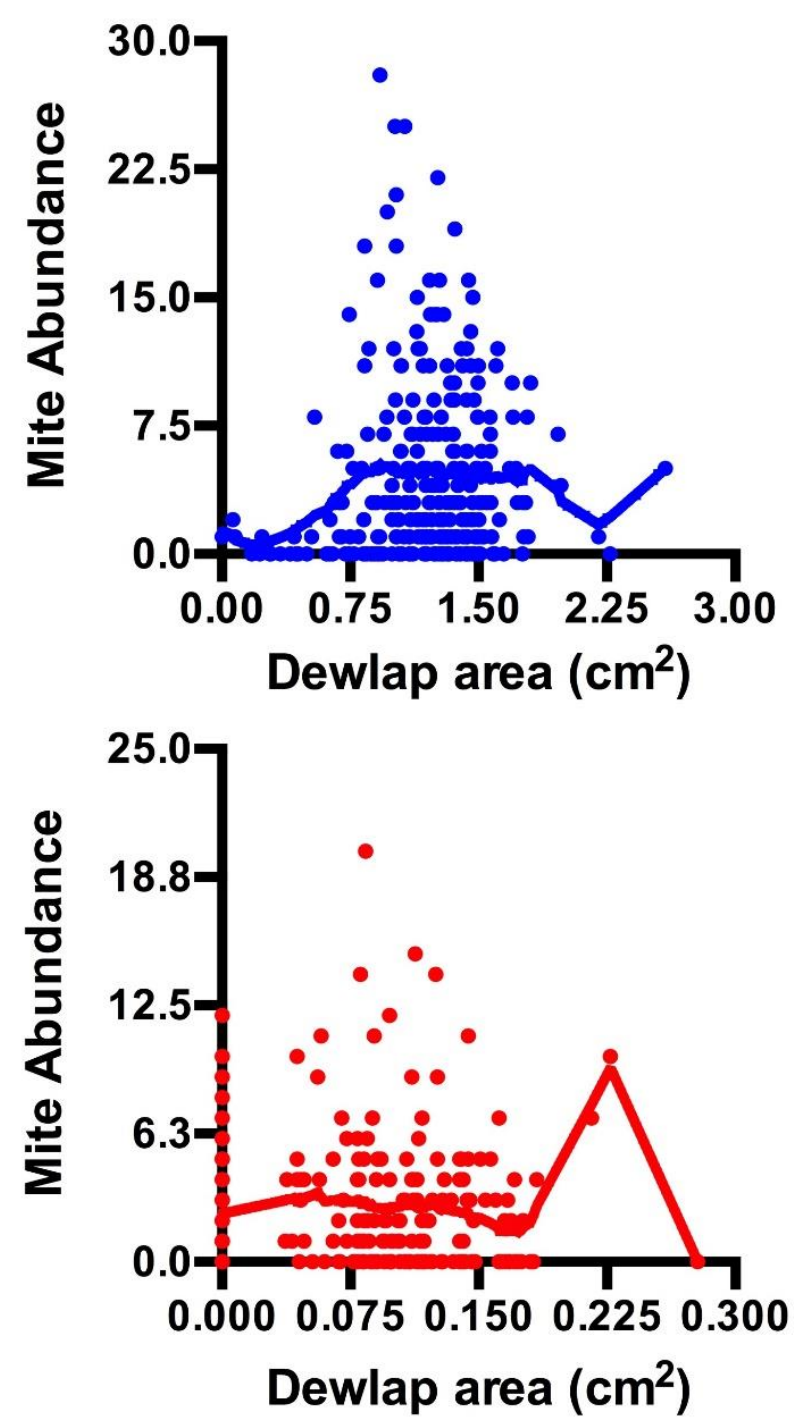

775

776 Figure 4. Relationship between mite abundance and area of the dewlap for males (top) and

777 females (bottom). Lines are LOWESS (locally weighted scatterplot smoothing) to reflect linear

778 and non-linear components to the relationship between dewlap size and mite infection. 


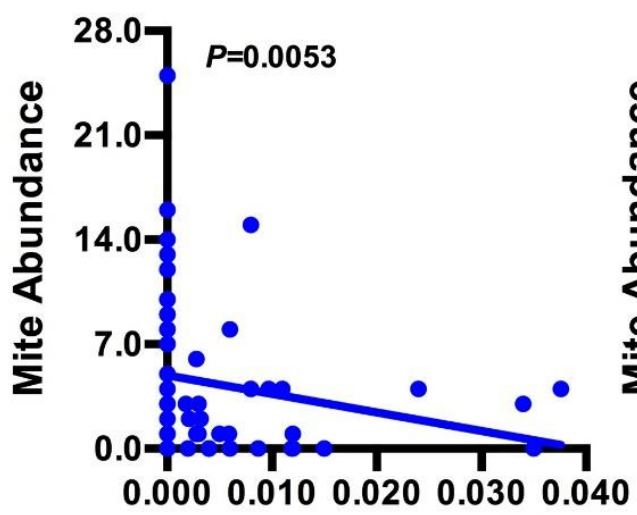

Fat Body Mass (g)

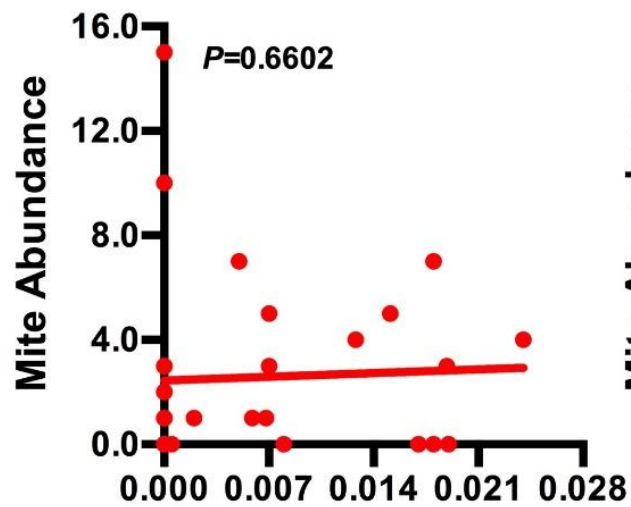

Fat Body Mass (g)
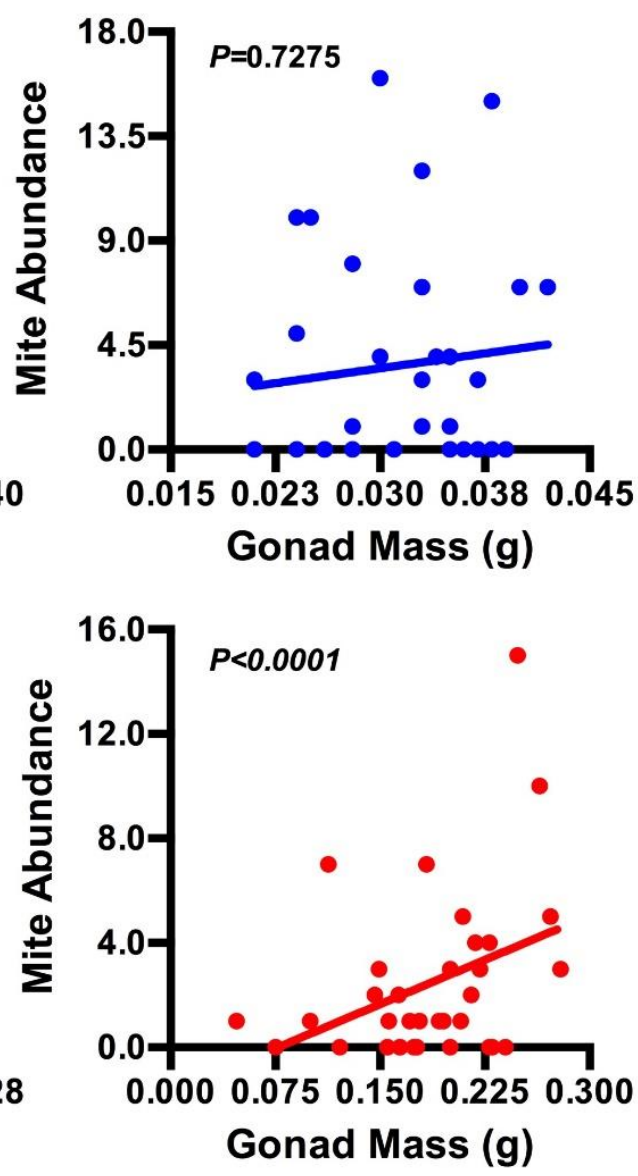

Figure 5. Relationship between fat body mass (left) and gonad (right) mass and mite abundance

781 for males (top) and females (bottom). Lines (middle and bottom) are best-fit lines from ordinary

782 least-square regression analyses. Mite abundance decreases with fat body mass for males but not

783 females, while gonad mass increases with mite abundance for females but not males. 